\author{
Jurnal E-Bis (Ekonomi-Bisnis) \\ Vol.5 No.1 (2021) pp. 83-99 \\ https://jurnal.politeknik-kebumen.ac.id/index.php/E-Bis \\ p-ISSN : 2580-2062 e-ISSN : 2622-3368
}

\title{
Pengaruh Budaya Kerja Dan Kecerdasan Emosional Terhadap Kinerja Karyawan Dengan Kepuasan Kerja sebagai Variabel Mediasi Pada PT. Matahari Department Store Tbk.
}

Feny Febrina Winandar ${ }^{1 *}$,I Ketut R.Sudiarditha ${ }^{2}$, Dewi Susita ${ }^{3}$
${ }^{123}$ Magister Manajemen, Universitas Negeri Jakarta, Indonesia

*Email : fewinandar@gmail.com

Doi : https://doi.org/10.37339/jurnal e-bis.v5i1.433

Diterbitkan oleh Politeknik Dharma Patria Kebumen

Info Artikel

Diterima :

2021-02-07

Diperbaiki :

2021-02-15

Disetujui :

2021-02-17

\begin{abstract}
ABSTRAK
DaIam peneIitian ini diteIiti pengaruh Budaya Kerja dan Kecerdasan EmosionaI terhadap Kinerja Karyawan dengan Kepuasan Kerja sebagai VariabeI Mediasi. PeneIitian ini merupakan peneIitian kuantitatif dengan data primer, structuraI equation modeIing (sem) digunakan untuk menganaIisis data yang teIah didapat dari PT Matahari. Berdasarkan kriteria yang teIah ditentukan, peneliti mendapatkan 200 data responden yang dianalisis dengan menggunakan software amos. HasiI peneIitian ini menunjukkan bahwa budaya kerja, kecerdasan emosionaI dan kepuasan berpengaruh terhadap kinerja karyawan. Serta kepuasan dapat memediasi pengaruh budaya kerja dan kecerdasan emosionaI terhadap kinerja karyawan.
\end{abstract}

Kata Kunci: Budaya, Kecerdasan Emosional, Kinerja

\begin{abstract}
This study examines the influence of work culture and emotional intelligence on employee performance with job satisfaction as a mediating variable. This research is a quantitative research with primary data, structural equation modeling (sem) is used to analyze the data that has been obtained from PT Matahari. Based on predetermined criteria, the researcher obtained 200 respondent data which were analyzed using amos software. The results of this study indicate that work culture, emotional intelligence and satisfaction affect employee performance. And satisfaction can mediate the influence of work culture and emotional intelligence on employee performance
\end{abstract}

Keywords: Culture, Emotional Intelligence, Performance

Alamat Korespondensi $\quad$ : Jl. Letnan Jenderal Suprapto No.73 Kebumen, Jawa Tengah, Indonesia 55431 


\section{PENDAHUIUAN}

Berbagai gejoIak perubahan yang terjadi pada lingkungan bisnis, menuntut individu maupun organisasi untuk meIakukan penyesuaian termasuk daIam bidang SDM. Penyesuaian ini dapat diIakukan meIaIui praktik manajemen perubahan, di mana terjadi proses penyejajaran yang berkeIanjutan antara organisasi dengan pasarnya, dan meIakukannya secara Iebih tanggap daripada para pesaingnya. Upaya untuk berhasiI meIakukan perubahan harus dimuIai dengan memastikan adanya cukup orang yang bertindak dengan urgensi yang memadai. HaI ini dapat terwujud jika organisasi sigap mengidentifikasi peIuang dan potensi masaIah yang mungkin akan dihadapi organisasi di masa mendatang. Perubahan terjadi di semua sektor bisnis dan organisasi termasuk sektor riteI.Industri riteI terus mengaIami pertumbuhan dan kapitaIisasi yang cukup signifikan, setiap tahunnya tumbuh 7-10\%.

PT Matahari Department Store Tbk, sebagai entitas bisnis daIam industri riteI fashion, harus dapat menjawab tantangan perubahan kepada para stakehoIders. Hingga tahun 2019 Matahari memiliki 169"gerai"di 76 kota"di seIuruh Indonesia"serta"gerai onIine, MATAHARI.com yang menawarkan fIeksibilitas dan pilihan yang terbaik daIam berbeIanja (AnnuaI Report, 2019). Berbagai invoasidilakukan oleh PT. Matahari Tbk, meski tergolong sebagai perusahaan yang telah matang dari segi usia maupun pengalaman dalam menghadapi tantangan perubahan. Setiap tahunnya PT Matahari Department Store Tbk memiliki target yang harus dipenuhi, salah satunya yaitu penambahan toko yang dilakukan setiap tahunnya. Pada tahun 2020 menargetkan toko yang akan dibuka sebanyak 7 gerai, hal ini dilakukan karena PT Matahari Department Store Tbk sedang melakukan ekspansi ke kota-kota kecil di luar pulau Jawa Indonesia. Walaupun di sisi lain menutup 2 gerai yang tidak produktif pada tahun 2019.laba bersih Matahari Department Store anjlok 42,5 persen di tahun 2018. Perusahaan hanya berhasil meraup laba bersih sebesar Rp1,1 triliun. Turun jauh dibanding keuntungan bersih 2017 yang mencapai Rp1,91 triliun. Di tahun 2019 terjadi peningkatan menjadi Rp1,36 triliun. Saat ini semakin banyak konsumen yang berbelanja online karena harga yang ditawarkan lebih murah dan praktis ketimbang belanja offline.Toko online dianggap lebih memiliki daya saing.Sayangnya hal tersebut belum terjadi pada Matahari.com, aplikasi daring milik Matahari Department Store. Toko online menjadi tantangan tersendiri bagi PT Matahari Departemen Store Tbk (Annual Report, 2019)

Berdasarkan CNBC Indonesia (Wareza, 2020), Matahari Tbk. mengumumkan penutupan sementara semua gerai secara nasional selama PSBB berlangsung sebagai langkah untuk menjaga kesehatan para karyawan. Selain itu, Matahari juga mengurangi beban usaha yang tidak esensial termasuk beban sewa, pemasaran, perjalanan dinas, dan beban lainnya, serta menghapuskan semua non-committed capital expenditure (belanja modal non-komitmen) di tahun 2020. Berkaitan dengan karyawan, Matahari mengurangi beban SDM melalui penurunan gaji 12.080 karyawannya hingga 50\%, dengan komponen penurunan terbesar berada di tingkat manajemen senior. Walaupun tidak melakukan PHK, namun Matahari Tbk. terpaksa merumahkan 5.623 karyawannya. 
Penurunan gaji tersebut berdampak terhadap karyawan yang memiliki kinerja tinggi, selain itu ancaman dirumahkan juga membuat karyawan bekerja di tengah ketidakpastian. Sekitar 1600 karyawan tercatat telat hadir atau absen (tidak hadir) di tengah jam kerja. Terdapat kemungkinan karyawan tersebut mulai mencari pekerjaan lain tau melakukan usaha sampingan. Berdasarkan data internal bidang SDM terjadi penurunan kinerja khususnya pada karyawan tingkat (grade) 2 yang ditunjukkan oleh data Performance Appraisal (PA), sebagai berikut:

Tabel 1.1

Performance Appraisal Karyawan Grade 2 PT Matahari Tbk

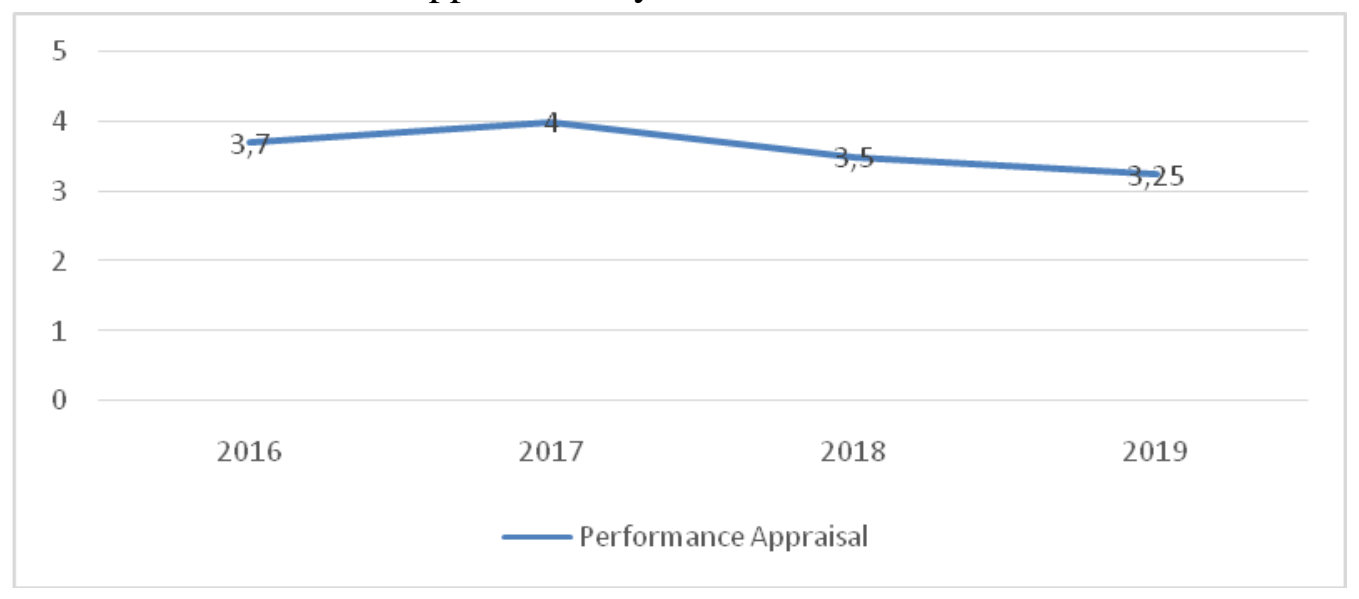

Berdasarkan data di atas terlihat penurunan yang cukup drastis dari kinerja karyawan khususnya karyawan tingkat 2 seIama dua tahun terakhir.Komponen peniIaian dari performance appraisaI diantaranya adaIah nilai faktor objektif (NiIai EBITDA perusahaan) dan niIai faktor subjektif (hasiI kerja masing-masing sesuai goIongan dan komponen sikap). Kinerja dari karyawan goIongan 2, naik di tahun 2017dari 3,7 menjadi 4 dan menurun sejak tahun 2018 kemudian semakin menurun di tahun 2019 menjadi 3,5 dan 3,25 seIama dua tahun terakhir. Penurunan tersebut mengganggu kinerja organisasi secara keseIuruhan.

Kinerja karyawan menjadi penting dalam menghadapi tantangan di era disrupsi.Agar memiliki keunggulan kompetitif dalam industri ritel, Matahari Tbk harus memiliki karyawan yang baik keduanya secara fisik dan mental.Karyawan yang memiliki kecerdasan emosional dapat menyesuaikan diri dengan baik terhadap perubahan yang terjadi termasuk dalam era Pandemi Covid-19.Peneliti melakukan wawancara kepada beberapa manajer toko menyatakan bahwa tingkat emosional karyawan tidak stabil bagi toko yang terancam tutup, di sisi lain karyawan memiliki tingkat emosional yang stabil bagi toko yang baru buka maupun yang sedang berkembang.Di tahun 2020, terdapat 6 gerai yang tutup dan 3 gerai yang baru buka, dalam hal ini pergantian karyawan sangat dinamis. Selain itu, penurunan gaji hingga 50\% terhadap 12.080 karyawan, dan merumahkan 5.623 karyawan, merupakan langkah berat yang harus ditempuh Matahari Tbk. Tidak sedikit karyawan yang kecewa dan mengalami stress. Dikarenakan banyaknya tanggung jawab yang diberikan kepada karyawan di toko oleh karena itu karyawan harus mempunyai kredibilitas, integritas dan kompetensi yang mumpuni, salah satunya adalah mampu mengelola emosi atau kecerdasan emosional dalam menjalankan fungsinya. 
Selain fenomena yang terjadi di atas, dalam penelitian-penelitian sebelumnya masih terdapat perbedaan hasil penelitian antara pengaruh kecerdasan emosional, budaya kerja dan kepuasan kerja terhadap kinerja Karyawan. Penelitian yang dilakukan oleh (Puyod \& Charoensukmongkol, 2019) dan (Kumari \& Singh, 2018) budaya berpengaruh positif terhadap kinerja. (Desky, 2014) serta (Zukarnaen et al., 2020) juga menguatkan bahwa budaya dan kepuasan berpengaruh terhadap kinerja karyawan. Di sisi lain penelitian yang dilakukan oleh (Ali \& Agustian, 2018)menyatakan kepuasan tidak berpengaruh terhadap kinerja karyawan, selain itu hasil penelitiannya juga menyatakan bahwa budaya berpengaruh terhadap kepuasan kerja. (Abdullah et al., 2014) dan (Supriyanto \& Troena, 2012) menyatakan bahwa kecerdasan emosional berpengaruh terhadap kinerja karyawan. (Madali et al., 2014), menemukan hasil bahwa kecerdasan emosional tidak berpengaruh terhadap kinerja Karyawan. (Gong et al., 2020) menyatakan bahwa kecerdasan emosional berpengaruh negatif terhadap kinerja karyawan. (Utama et al., 2016) yang menggunakan variabel kepuasan sebagai variabel mediasi menemukan bahwa kecerdasan emosional berpengaruh terhadap kinerja organisasi. Ditinjau dari hasil penelitian terdahulu tersebut pengaruh budaya, kecerdasan emosional dan kepuasan dengan kinerja karyawan masih terdapat kontroversi hasil beberapa peneliti (research gap).

Berdasarkan latar belakang permasalahan, fenomena gap dan researchgap tersebut peneliti mengambil judulpengaruh kecerdasan emosional dan budaya kerja terhadap kinerja karyawan dengan kepuasan kerja sebagai variabelmediasi.

\section{KAJIAN PUSTAKA}

\subsection{Manajemen SDM}

Manajemen sumber daya manusia, disingkat MSDM, adalah suatu ilmu atau cara bagaimana mengatur hubungan dan peranan sumber daya (tenaga kerja) yang dimiliki oleh individu secara efisien dan efektif serta dapat digunakan secara maksimal sehingga tercapai tujuan (goal) bersama perusahaan, karyawan dan masyarakat menjadi maksimal. (Nedaee et al., 2012) menyatakan bahwa "Human resource management is a continuous procedure that aims to supply a company with the right people to be placed in the right positions and positions when the organization needs them". Dalam artian manajemen sumber daya manusia adalah suatu prosedur yang berkelanjutan yang bertujuan untuk memasok suatu perusahaan dengan orang-orang yang tepat untuk ditempatkan pada posisi dan jabatan yang tepat pada saat organisasi memerlukannya.

\subsection{Kinerja Karyawan}

Kinerja dalam suatu pekerjaan berkaitan dengan tindakan dalam melakukan pekerjaan. Kinerja adalah sarana untuk mencapai tujuan atau serangkaian tujuan dalam suatu pekerjaan, peran, atau organisasi, tetapi bukan konsekuensi aktual dari tindakan yang dilakukan dalam suatu pekerjaan. (Dinata, 2018) menegaskan bahwa kinerja pekerjaan bukanlah tindakan tunggal 
tetapi lebih merupakan aktivitas yang kompleks. Kinerja dalam suatu pekerjaan merupakan perilaku. Kinerja pekerjaan dapat didefinisikan sebagai nilai tertentu yang diharapkan oleh organisasi dari aktivitas kompleks yang dilakukan seseorang selama periode waktu tertentu.Salah satu gagasan penting dalam definisi ini adalah bahwa kinerja merupakan bagian dari sifat dan perilaku. Secara khusus, kinerja merupakan perilaku yang terjadi selama beberapa rentang waktu tertentu. Gagasan penting kedua adalah bahwa sifat perilaku yang merujuk kinerja adalah nilai yang diharapkan untuk organisasi.

\subsection{Budaya Organisasi}

Budaya organisasi merupakan unsur penting dari kinerja dan sumber keunggulan kompetitif yang berkelanjutan bagi organisasi.Budaya organisasi merupakan elemen penting dalam menyatukan berbagai budaya perusahaan.Manajer perusahaan dapat membangun budaya yang efektif dan terintegrasi sehingga meningkatkan kinerja organisasi.Menurut (Robbins \& Timothy, 2014) "Organizational culture is a system of shared meaning held by members that distinguishes the organization from other organizations. Maksudnya budaya organisasi adalah sistem makna bersama yang dipegang oleh anggota yang membedakan organisasi dari organisasi lain. Setiap organisasi terdapat pola mengenai kepercayaan ritual, mitos, serta praktik-praktik yang telah berkembang sejak lama, dimana budaya organisasi diturunkan dari filsafat pendiri, kemudian budaya ini sangat mempengaruhi kriteria yang digunakan dalam merekrut atau mempekerjakan anggota organisasi.

\subsection{Kecerdasan Emosional}

Menurut (Budiono \& Wibowo, 2014), kecerdasan emosional yaitu mengendalikan hati dan dapat menghadapi stress serta memotivasi diri untuk lebih baik lagi. Karyawan yang memiliki kecerdasan emosional mampu mengatur suasana hati dan menjaga agar beban stress tidak melumpuhkan kemampuan berpikir, berempati danberdoa. Kecerdasan emosional berisi ilmu mengenai keterampilan seseorang untuk memahami emosi yang dialami dirinya dan juga pada orang lain sehingga dapat menggunakannya untuk mendapatkan hasil yang diinginkan dari diri sendiri maupun orang lain.

\subsection{Kepuasan Kerja}

Pada dasarnya kepuasan kerja merupakan suatu hal yang bersifat individu. Setiap individu akanmemiliki tingkat kepuasan yang berbeda-beda sesuai dengan sistem nilai-nilai yang berlaku pada dirinya. Hal ini disebabkan karena adanya perbedaan pada masing-masing individu.Dengan semakin banyaknya aspek-aspek dalam pekerjaan yang sesuai dengan keinginan individu tersebut, maka semakin tinggi tingkat kepuasan kerja yang dirasakannya dan sebaliknya. Kepuasan kerja adalah sikap umum terhadap pekerjaan seseorang yang menunjukkan perbedaan antara jumlah penghargaan yang diterima pekerja dan jumlah yang mereka yakini seharusnya mereka terima (Rozanna et al., 2019). Kepuasan kerja (job satisfaction) menurut(Cook, 2008)didefinisikan sebagai "a positive feeling about the job that results from evaluating its characteristics" maksudnya suatu perasaan positif tentang pekerjaan 
seseorang yang merupakan hasil dari evaluasi karakteristiknya. Seseorang dengan tingkat kepuasan kerja yang tinggi memiliki perasaan-perasaan positif tentang pekerjaan tersebut, sementara seseorang yang tidak puas memiliki perasaan-perasaan yang negatif tentang pekerjaan tersebut. Orang yang merasa puas menganggap kepuasan sebagai suatu rasa senang dan sejahtera karena dapat mencapai suatu tujuan atau sasaran. Dimensi dan indikator yang biasa digunakan untuk mengukur kepuasan kerja seorang karyawan menurut Herzberg dalam (Hwang, 2019), yaitu pekerjaan itu sendiri (work it self), Balas jasa (pay), promosi (promotion), pengawasan(supervision), rekan kerja (workers).

\subsection{Kerangka Kerja}

Berdasarkan teori diatas, untuk menggambarkan hubungan antara variabel budaya kerja, kecerdasan emosional, kepuasan dan kinerja dapat digambarkan dalam model penelitian sebagai berikut:

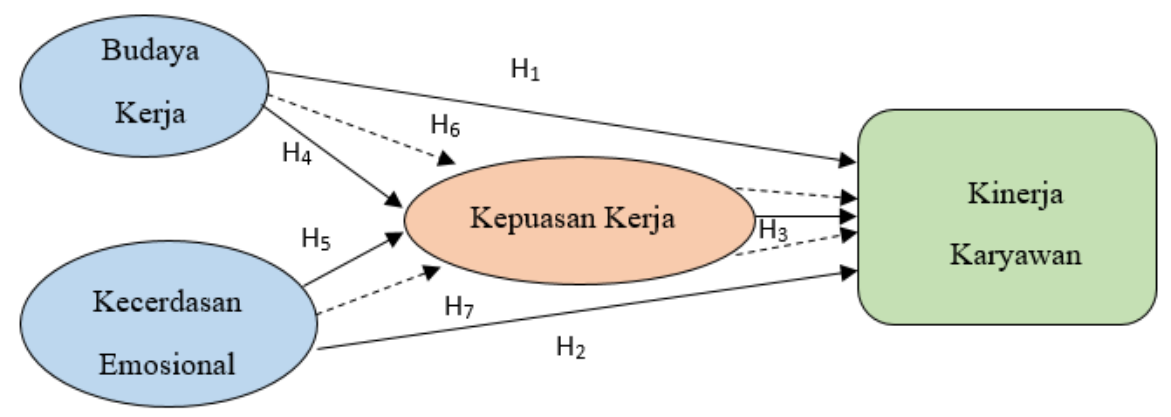

\section{Gambar 2.1.Hubungan antara budaya kerja, kecerdasan emosional, kepuasan kerja dengan kinerja.}

\section{METODE}

Tahap awal dari penelitian ini adalah dengan melakukan studi pendahuluan dengan cara menanyakan segala hal yang berkaitan dengan penelitian ini kepada pimpinan dan manajer SDM. Dari hasil wawancara tersebut diperoleh data bahwa telah terjadi penurunan kinerja secara umum yang terlihat pada tahun 2017 menuju 2018 serta beberapa indikator di tahun 2019 . Kemudian dilakukan identifikasi terhadap beberapa kemungkinan penyebab, dimana di antaranya adalah budaya organisasi, kecerdasan emosional dan kepuasan kerja. Penelitian ini menggunakan metode penelitian kuantitatif dengan data primer (metode survey) untuk mencari hubungan antara variabel independen yaitu kecerdasan emosional $\left(\mathrm{X}_{1}\right)$, budaya organisasi $\left(\mathrm{X}_{2}\right)$ dan kepuasan kerja $(\mathrm{Xm})$ sebagai variabel mediasi terhadap variabel dependen yaitu kinerja karyawan (Y). Penelitian ini menggunakan angket sebagai alat penelitian yang dilakukan pada objek penelitian sehingga ditemukan kejadian relatif, distribusi dan hubungan antar variabel, sosiologi maupun psikologis.Studi pustaka dan literatur dilakukan untuk mencari teori-teori dan data yang digunakan dalam mendukung topik-topik yang diteliti.Berdasarkan data internal 
(2019) jumlah sampel dalam penelitian ini adalah 210 orang responden yakni Karyawan level manajer Grade 2 yang bekerja di Head Office PT Matahari Departemen Store.

\section{HASII DAN PEMBAHASAN}

\subsection{Deskripsi PT Matahari}

PT Matahari teIah menginspirasi dan menyenangkan keIuarga Indonesia seIama 60 tahun, dan kami berkomitmen untuk meningkatkan warisan ini seiring dengan kemajuan kami.maksud dan tujuan Perseroan adaIah untuk menjaIankan bisnis di bidang berikut: riteI, konveksi, perdagangan umum, agensi, dan perwakiIan; dan untuk meIaksanakan kegiatan usaha yang dibutuhkan untuk menjaIankan suatu bisnis, pengembangan bisnis, menyediakan jasa umum termasuk jasa konsuItasi manajemen, serta manajemen perusahaan, baik atas nama sendiri atau meIaIui anak perusahaan. Perusahaan menjuaI berbagai jenis produk, dengan merek ekskIusif sendiri dan secara konsinyasi. Produk tersebut meliputi pakaian, aksesoris, tas, sepatu, kosmetik, peraIatan rumah tangga dan peraIatan rumah tangga. SeIain itu, Perseroan menyediakan Iayanan Iogistik kepada konsumen pihak ketiga, yang dioperasikan oIeh anak perusahaannya, yaitu PT Matahari Nusantara Iogistik.

PT Matahari Department Store Tbk. memiliki niIai budaya dan periIaku-periIaku yang dinyatakan daIam butir-butir FiIosofi Matahari yang menjadi pedoman dan budaya organisasi diantaranya: Matahari berusaha menciptakan tingkat hidup yang lebih baik bagi seluruh karyawan. Matahari berusaha menciptakan tempat kerja yang aman, nyaman, tentram dan sejahtera, sebagai pancaran cita-cita karyawan. Matahari berusaha menciptakan sistem organisasi operasional terpadu, demi masa depan perusahaan dan karyawan atas dasar efisiensi kerja yang maksimal. Matahari berusaha mendidik, melatih dan mengembangkan seluruh karyawan yang merata, tanpa membedakan tradisi, agama, asal keturunan, sadar akan tugas dan kewajiban, menjunjung tinggi tujuan perusahaan sebagai penunjang perekonomian bangsa. Matahari berharap atas dasar sinkronisasi, saling percaya mempercayai, hormat menghormati, kerja sama yang baik dengan azas kekeluargaan, untuk mencapai kemajuan yang kekal dan abadi.

\subsection{Pembahasan}

Berdasarkan hasil AMOS 20 dan SPSS versi 25 pada pengujian sebelumnya, kemudian ditelaah lebih lanjut untuk menerima atau menolak hipotesis yang terdapat dalam penelitian ini, maka dapat dijelaskan pada hasil uji hipotesis sebagai berikut ini:

\section{a. Pengaruh Kecerdasan Emosional Terhadap Kinerja Karyawan}

HasiI uji hipotesis diperoIeh hasiI parameter estimasi yang didapat antara kecerdasan emosionaIdengan kinerja karyawan dengan niIai CR 3,504 dimana nilai tersebut memenuhi syarat $\mathrm{CR}>1,96$ dan nilai Probability $=0,000$ juga memenuhi syarat tingkat signifikasi 5\% (Prob <0,05). Berdasarkan hasiI uji,"variabeI Kecerdasan EmosionaI memiliki pengaruh positifdan signifikan KenganvariabeI Karyawan 


\section{Feny Febrina Winandar ${ }^{1^{*}}$, I Ketut R.Sudiarditha ${ }^{2}$, Dewi Susita ${ }^{3}$}

3

sepertiyangdipaparkan"diatas.Jika"Kecerdasan EmosionaI karyawan dikelola secara tepat maka dapat meningkatkan Kinerja Karyawan PT Matahari.Fakta di lapangan menjelaskan bahwa Kecerdasan Emosional yang tepat dapat meningkatkan Kinerja Karyawan. Responden menyampaikan daIam wawancara singkat bahwa karyawan PT Matahari yang memiliki kecerdasan emosionaI tinggi memiliki kemampuan untuk memotivasi diri sendiri, mengendalikan dorongan hati, mengatur suasana hati dan menjaga agar tidak stres sehingga dapat mengoptimaIkan potensi kinerjanya dan mendapatkan hasiI yang diinginkan. DaIam haI ini, untuk meningkatkan kinerja karyawan diperIukan pengeIoIaan kecerdasan emosionaI yang baik.

Sesuai dengan teori tripIe bottom Iine dijeIaskan bahwa konsep pengukuran kinerja bukan hanya dijeIaskan dari peroIehan profit tapi juga kepedulian terhadap peopIe termasuk karyawan di daIamnya, dan Iingkungan. Kecerdasan emosionaI secara tidak Iangsung, menekankan kepada PT Matahari untuk memahami SDM (karyawan) sebagai manusia dan mahkIuk sosiaI yang memiliki emosi, di sisi lain karyawan juga perlu mengelola dirinya dalam hal emosional. Hasil ini didukung oleh penelitian (Mandala, 2018), dalam penelitiannya yang berjudul pengaruh kecerdasan emosional dan kecerdasan spiritual terhadap kinerja karyawan PT. Madu Baru Bantul, menjelaskan bahwa kecerdasan emosional dan spiritual berpengaruh terhadap kinerja karyawan. Kemudian hasil ini dikuatkan oleh (Putri, Sari \& Wirajaya, 2019) dengan judul the effect of love of money and emotional intelligence on employee performance with organizational citizenship behavior as mediating variable dan (Koronios et al., 2019) dengan judul Emotional Intelligence of Employees in the Hospitality Sector: Exploring Its Effects on Job Satisfaction and Performance, hasilnya menyatakan bahwa kecerdasan emosional berpengaruh terhadap kinerja karyawan. Purnama (2014), menemukan hasil bahwa kecerdasan emosional tidak berpengaruh terhadap kinerja Karyawan.(Gong et al., 2020) dengan judulThe Influence of Emotional Intelligence on Job Burnout and Job Performance: Mediating Effect of Psychological Capital menyatakan bahwa kecerdasan emosional berpengaruh negatif terhadap kinerja karyawan. Kecerdasan emosionalakan membantu untuk meningkatkan modal psikologis mereka, dan modal psikologis yang tinggi akan menyebabkan kinerja pekerjaan yang positif dan mengurangi kelelahan kerja. Berdasarkan hasilpenelitian, dapat disimpulkan terdapat hubungan positif kecerdasan emosional terhadap kinerja karyawan.

\section{b. PengaruhBudaya Kerja Terhadap Kinerja Karyawan}

Dari hasiI pengujian diperoIeh hasiI parameter estimasi yang didapat antara budaya kerja dengan kinerja karyawan dengan nilai CR 2,385 dimana niIai tersebut memenuhi syarat CR $>1,96$ dan niIai Probability = 0,017 juga memenuhi syarat tingkat signifikasi 5\% (Prob <0,05). Berdasarkan hasiIpengujian, variabel'budaya kerja memiliki pengaruh positif signifikan denganvariabeI Kinerja Karyawan sepertiyangdipaparkan"diatas.

Fakta di Iapangan menjeIaskan bahwa Budaya kerja yang dikeIoIa dengan baik dapat meningkatkan Kinerja Karyawan. Responden menyampaikan daIam wawancara singkat bahwa 


\section{Feny Febrina Winandar ${ }^{1^{*}}$, I Ketut R.Sudiarditha ${ }^{2}$, Dewi Susita ${ }^{3}$}

3

karyawan PT Matahari yang meIaksanakan budaya kerja berdampak daIam memberikan rasa identitas bagi anggota-anggota organisasi, mendorong stabilitas sistem sosiaI, membentuk rasa dan kendali yang memberikan panduan dan membentuk sikap serta periIaku karyawan agar Iebih produktif daIam bekerja. HasiI ini didukung oIeh(AIi \& Agustian, 2018) budaya organisasi atau perusahaan yang menyatakan bahwa niIai-niIai yang menjadi pegangan sumber daya manusia daIam menjaIankan kewajiban dan perilakunya di daIam organisasi dapat meningkatkan kinerja organisasi. NiIai-niIai tersebut yang akan memberi jawaban apakah suatu tindakan benar atau saIah dan apakah suatu perilaku dianjurkan atau tidak sehingga berfungsi sebagai Iandasan untuk berperiIaku.

Penelitian ini diperkuat oIeh (AIia \& Rohani, 2015) bahwa budaya berpengaruh positif dan signifikan terhadap kinerja karyawan.(Puyod \& CharoensukmongkoI, 2019) dengan juduIthe contribution of cuItural inteIIigence to the interaction invoIvement and performance of caII center agents in cross-cuIturaI communication: the moderating role of work experience, daIam penelitiannya dijeIaskan bahwa budaya berpengaruh positif terhadap kinerja. HasiI tersebut dikuatkan oIeh (Dania, 2020) dengan juduI OrganizationaI CuIture, Job Satisfaction, and Employee Performance (Case Study in PT. GMT Jember) yang menganalisis pengaruh budaya organisasi terhadap kinerja karyawan dengan komitmen organisasi sebagai variabeI intervening pada PT. GMT Jember dengan 30 responden memperoleh kesimpuIan bahwa budaya organisasi berpengaruh positif signifikan terhadap kinerja karyawan. Kemudian (Iin \& Huang, 2020) dengan juduIempIoyee turnover intentions and job performance from a pIanned change: the effects of an organizationaIlearning cuIture and job satisfaction juga menguatkan bahwa budaya dan kepuasan berpengaruh terhadap kinerja karyawan. DaIam menghadapi lingkungan yang berubah dan bergejoIak, budaya organisasi menjadi sangat penting untuk operasi jangka panjang organisasi.Budaya memberikan kapasitas untuk mengintegrasikan karyawan secara efektif daIam mencapai kinerja yang optimaI.Berdasarkan hasilpenelitian, dapat disimpuIkan budaya berpengaruh positif terhadap kinerja.

\section{c. Pengaruh Kepuasan Berpengaruh Terhadap Kinerja Karyawan}

Dari hasiI pengujian diperoIeh hasiI parameter estimasi yang didapat antara kepuasan kerja dengan kinerja karyawan dengan niIai CR 2,954 dimana nilai tersebut memenuhi syarat CR >1,96 dan nilai Probability $=0,003$ juga memenuhi syarat tingkat signifikasi 5\% (Prob $<0,05)$.

Berdasarkan hasiI uji, variabeIkepuasan kerja memiliki pengaruhpositif signifikan denganvariabeI Kinerja Karyawan yangdipaparkandiatas.Fakta di Iapangan menjeIaskan bahwa responden atau karyawan PT Matahari menginginkankepuasan yang mencukupi dirinya, misaInya seperti gaji yang wajar, karena uang merupakan insentif yang paIing penting, ketika gaji terhambat atau berkurang karena faktor tertentu maka kinerja menjadi tidak optimaI. Setiap individu akan memiliki tingkat kepuasan yang berbeda-beda sesuai dengan sistem niIai-niIai yang berIaku pada dirinya. HaI ini disebabkan karena adanya perbedaan pada masing-masing individu. SeIain pembayaran gaji, kepuasan kerja juga memiliki dimensi Iain seperti pengawasan, promosi, pekerjaan itu sendiri dan kondisi kerja. Departemen personalia atau pihak 


\section{Feny Febrina Winandar ${ }^{1^{*}}$, I Ketut R.Sudiarditha ${ }^{2}$, Dewi Susita ${ }^{3}$}

3

manajemen PT Matahari senantiasa memonitor kepuasan kerja, karena haI ini dapat mempengaruhi tingkat absensi, perputaran tenaga kerja, semangat kerja, keIuhan-keIuhan dan masaIah personalia Iainnya yang dapat berpengaruh pada kinera karyawan.

HasiI ini dikuatkan oIeh penelitian (Dania, 2020) dengan juduI'OrganizationaI CuIture, Job Satisfaction, and Employee Performance"(Case Study in PT. GMT Jember) yang memperoleh hasiI bahwa"kepuasan kerja berpengaruh positif signifikan terhadap kinerja"karyawan.Karyawan dianggap sebagai keIompok yang memiliki kebutuhan yang harus dipenuhi agar kinerjanya optimaI.Kemudian (Iin \& Huang, 2020) dengan juduIempIoyee turnover intentions and job performance from a planned change: the effects of an organizationaIIearning cuIture and job satisfaction menguatkan bahwa"kepuasan berpengaruh terhadap"kinerja karyawan. Karyawan pada PT Matahari memiliki kebutuhan beragam, jika perusahaan dapat memahami urgensi dan proporsionaInya dengan baik tentu dapat menjadi kekuatan daIam meningkatkan kinerja.HasiI penelitian tersebut juga didukung oIeh (Gibson et aI., 2000), (Rozanna et aI., 2019) serta(Hidayat, 2013), menyatakan bahwa terdapat dampak yang siginifikan antara"kepuasan kerja terhadap kinerja karyawan dan karyawan yang puas"akan memiliki komitmen yang tinggi daIam bekerja. Senada dengan peneIitian sebeIumnya (FunmiIoIa et aI., 2013) menyatakan bahwa dimensi dari kepuasan kerja (pembayaran, pengawasan, promosi, dan kondisi kerja)"memiliki pengaruh yang signifikan terhadap kinerja"karyawan. Karyawan yang memiliki kepuasan yang Iebih tinggi akan menunjukkan kinerja pekerjaan yang Iebih baik. Di sisi Iain, peneliti hanya menemukan (Agustina, 2018) yang mendapatkan hasiI yang bertentangan bahwa"kepuasan tidak berpengaruh terhadap kinerja"karyawan.

\section{d. Pengaruh Budaya Kerja Terhadap Kepuasan}

Dari hasil pengujian diperoleh hasil parameter estimasi yang didapat antara budaya kerja dengan kepuasan kerja karyawan dengan nilai CR 2,319 dimana nilai tersebut memenuhi syarat CR $>1,96$ dan nilai Probability $=0,020$ juga memenuhi syarat tingkat signifikasi 5\% (Prob $<0,05)$. Berdasarkan hasil uji, variabel budaya kerja memiliki pengaruh positif signifikan denganvariabel Kepuasan kerja Karyawan yangdipaparkandiatas.Fakta di lapangan menjelaskan bahwa responden atau karyawan PT Matahari mengalami penurunan budaya, misalnya pada poin budaya "Menciptakan tingkat hidup yang lebih baik bagi seluruh karyawan". Budaya tersebut mengalami penurunan di setiap tahunnya (data laporan tahunan PT Matahari), yang diikuti dengan menurunnya kepuasan yang dirasakan karyawan.Beberapa budaya yang mengalami penurunan disebabkan oleh pengendalian yang minim terhadap budaya tersebut. Karyawan menjadi kurang peduli terhadap budaya organisasi yang berdampak pada menurunnya kepuasan kerja.Dalam penerapan nilai dan budaya perusahaan, PT Matahari Tbk berusaha menciptakan lingkungan kerja yang inklusif di mana karyawan dapat bangga dengan pekerjaannya, tahu bahwa mereka dihargai oleh manajemen, dan merasa bahwa karyawan adalah bagian dari 'keluarga Matahari'.Budaya tersebut perlu ditingkatkan dengan baik sehingga karyawan merasa puas berada di dalam keluarga Matahari Tbk. 
Hasil penelitian ini didukung oleh (Sukardi, Bahri \& Tupti, 2020) dengan judul Pengaruh Kepemimpinan, lingkungan dan Budaya Terhadap Kepuasan Kerja Karyawan Umum dan Perlengkapan labura dengan menggunakan seluruh sampel menjadi populasi sebanyak 40 orang dan teknik analisis data menggunakan analisis regresi linier berganda, uji asumsi klasik uji t, uji $\mathrm{f}$ dan koefisien determinasi diperoleh hasil bahwa terdapat pengaruh budaya terhadap kepuasan kerja. Kemudian dikuatkan oleh (Imam dan Thoyib, 2015) dengan judulthe role of corporate culuture and employee motivation menyatakan bahwa budaya organisasi berpengaruh positif dan signifikan terhadap kepuasan kerja. (Baribin dan Saputri, 2020) dengan judul pengaruh budaya organisasi dan lingkungan kerja terhadap motivasi kerja serta dampaknya terhadap kepuasan kerja karyawan dengan sampel yang digunakan dalam penelitian ini adalah 215 responden dari karyawan tetap PT. Posmi Steel Indonesia dan tes statistik yang digunakan adalah validitas, reliabilitas, dan analisis jalur menyatakan hasil bahwa budaya organisasi mempengaruhi kepuasan kerja karyawan.

\section{e. Pengaruh Kecerdasan Emosional Terhadap Kepuasan}

Dari hasil pengujian diperoleh hasil parameter estimasi yang didapat antara kecerdasan emosional dengan kepuasan kerja karyawan dengan nilai CR 2,409 dimana nilai tersebut memenuhi syarat $\mathrm{CR}>1,96$ dan nilai Probability $=0,019$ juga memenuhi syarat tingkat signifikasi 5\% (Prob <0,05). Berdasarkan hasil uji, variabel kecerdasan emosional memiliki pengaruh positif signifikan denganvariabelkepuasan kerja karyawan yangdipaparkandiatas.Fakta di lapangan menjelaskan bahwa responden atau karyawan PT dapat mengelola emosionalnya dengan baik, tingkat stress dapat ditekan dengan berbagai strategi sehingga karyawan merasa puas berada di dalam organisasi.Menurut (Feldman, 2012) fungsi-fungsi yang penting dari emosi adalah mempersiapkan individu untuk bertindak yang mana hal ini merupakan bagaimana respon yang keluar dari dalam diri individu berdasarkan kejadian yang terjadi dilingkungannya.

Hasil ini dikuatkan oleh penelitian (Amalia et al., 2019) dengan judul Pengaruh Kecerdasan Emosional dan Kecerdasan Spiritual terhadap Kepuasan Kerja dan Kinerja"Manajer. Data dikumpulkan langsung dari responden dengan menggunakan instrumen penelitian berupa kuesioner dan teknis analisis data menggunakan PIS (Partialleast Square).Hasil penelitian membuktikan bahwa kecerdasan emosional berpengaruh signifikan terhadap kepuasan kerja, kecerdasan emosional berpengaruh signifikan terhadap kinerja, kepuasan kerja berpengaruh signifikan terhadap kinerja.(Mandala, 2018) dalam penelitiannya yang berjudul pengaruh kecerdasan emosional dan kecerdasan spiritual pada kepuasan kerja yang berdampak terhadap kinerja karyawan pt. madu baru bantul, menjelaskan bahwa kecerdasan emosional dan spiritual berpengaruh terhadap kepuasan kerja dan juga kinerja organisasi. (Madalali dan Purnama, 2014) menjelaskan bahwa Emotional Quotient berpengaruh terhadap kepuasan kerja, hasil penelitian lain juga pernah dilakukan oleh (Supriyanto \& Troena, 2012). Kecerdasan emosional memiliki pengaruh positif dan signifikan terhadap kepuasan kerja.Penelitian mengenai kecerdasan emosi 


\section{Feny Febrina Winandar ${ }^{1^{*}}$, I Ketut R.Sudiarditha ${ }^{2}$, Dewi Susita ${ }^{3}$}

3

terhadap kepuasan juga pernah dilakukan oleh (Suwandi, 2019), dengan hasil penelitian kecerdasan emosional berpengaruh positif dan signifikan terhadap kepuasan.

\section{f. Pengaruh Budaya Kerja Terhadap Kinerja Karyawan Dengan Kepuasan Sebagai Mediasi}

Dari hasil pengujian diperoleh hasil parameter estimasi yang didapat antara budaya kerja, kinerja dan kepuasan kerja telah memenuhi syarat nilai $\mathrm{P}=0,020$ juga memenuhi syarat tingkat signifikasi 5\% ( $\mathrm{P}<0,05)$. Dengandemikianini berarti hipotesis alternatif (Ha6) diterima.Sehingga Kinerja karyawan dari PT Matahari Tbk dipengaruhi oleh budaya kerja dengan dimediasi oleh kepuasan.

Hal tersebut didukung oleh hasil penelitian sebelumnya yang dilakukan oleh (Supriyanto \& Troena, 2012) diperoleh hasil bahwa terdapat pengaruh budaya terhadap kepuasan kerja. Kemudian (Rozanna et al., 2019), (lestari \& Wibawa, 2019), (Obiunu \& Yalaju, 2020) menyatakan bahwa terdapat dampak yang siginifikan antara kepuasan kerja terhadap kinerja karyawan. Jika PT Matahari mengelola budaya organisasi maka karyawan akan puas kemudian memiliki"kinerja yang tinggi dalam bekerja. Senada dengan penelitian sebelumnya,

(Dania, 2020) dengan judul Organizational Culture, Job Satisfaction, and Employee Performance (Case Study in PT. GMT Jember) yang menganalisis peran kepuasan sebagai mediasi dari pengaruh budaya organisasi terhadap kinerja karyawan dengan komitmen organisasi sebagai variabel intervening pada PT. GMT Jember memperoleh kesimpulan bahwa kepuasan kerja dapat memediasi dan budaya organisasi berpengaruh positif signifikan terhadap kinerja karyawan. Kemudian (lin \& Huang, 2020) dengan judul employee turnover intentions and job performance from a planned change: the effects of an organizationallearning culture and job"satisfaction juga menguatkan bahwa budaya dan kepuasan berpengaruh terhadap kinerja karyawan. Dalam menghadapi lingkungan yang berubah dan bergejolak, budaya organisasi menjadi sangat penting untuk operasi jangka panjang organisasi.

\section{g. Pengaruh Kecerdasan Emosional Terhadap Kinerja Karyawan Dengan Kepuasan Sebagai Mediasi}

Dari hasil pengujian diperoleh hasil parameter estimasi yang didapat antara kecerdasan emosional, kinerja dan kepuasan kerja telah memenuhi syarat nilai $\mathrm{P}=0,013$ juga memenuhi syarat tingkat signifikasi 5\% (P<0,05). Dengandemikianini berarti hipotesis alternatif (Ha7) diterima.Sehingga Kinerja karyawan dari PT Matahari Tbk dipengaruhi oleh kecerdasan emosional dan dimediasi oleh kepuasan kerja.Hasil ini diperkuat oleh (Putri, Sari \& Wirajaya (2019) dan (Koronios et.al., 2019) hasilnya menyatakan bahwa kecerdasan emosionalberpengaruh terhadap kinerja karyawan. Kemudian (Supriyanto \& Troena, 2012) dengan teknis analisis data menggunakan PIS (Partialleast Square) membuktikan bahwa kecerdasan emosional berpengaruh signifikan terhadap kepuasan kerja, kecerdasan emosional berpengaruh signifikan terhadap kinerja, dan kepuasan kerja berpengaruh signifikan terhadap kinerja. Kemudian diperkuat oleh (Gibson et al., 2000), (Rozanna et al., 2019), menyatakan 
bahwa terdapat dampak yang siginifikan antara kepuasan kerja terhadap kinerja Karyawan dan Karyawan yang puas akan memiliki komitmen yang tinggi dalam bekerja. Senada dengan penelitian sebelumnya (Hidayat, 2013) menyatakan bahwa dimensi dari kepuasan kerja (pembayaran, pengawasan, promosi, dan kondisi kerja) memiliki pengaruh yang signifikan terhadap kinerja Karyawan. Pada dasarnya kecerdasan emosionalakan membantu untuk meningkatkan modal psikologis (kepuasan karyawan), dan modal psikologis yang tinggi akan menyebabkan kinerja pekerjaan yang positif dan mengurangi kelelahan kerja.

\section{KESIMPUIAN}

Kesimpulan dari artikel ini adalah:

a. Budaya kerja berpengaruh positif dan signifikan terhadap kinerja karyawan. Artinya jika budaya kerja semakin kondusif, maka"akan meningkatkan kinerja karyawan.

b. Kecerdasan"emosionaI berpengaruh positif dan signifikan terhadapkinerja"karyawan. Artinya jika"kecerdasan emosionaI semakin naik maka akan dapat meningkatkan kinerja"karyawan.

c. Kepuasan"berpengaruh positif dan signifikan terhadap"kinerja karyawan. Artinya jika kepuasan naik maka akan mempengaruhi kenaikan kinerja"karyawan.

d. Budaya"kerja berpengaruh positif dan signifikan terhadap"kepuasan kerja. Artinya jika budaya kerja sesuai dengan kondisi prajurit maka akan meningkatkan kepuasan"kerja.

e. Kecerdasan"emosionaI berpengaruh positif dan signifikan terhadap"kepuasan. Artinya jika kecerdasan emosionaI semakin baik maka akan mempengaruhi kenaikan kepuasan"kerja.

f. Kepuasan"memediasi budaya kerja terhadapkinerja"karyawan. Artinya"budaya kerja berpengaruh terhadap kepuasan kerja dan kepuasan kerja berpengaruh terhadap"kinerja. Budaya kerja"dapat mempengaruhi kinerja meIaIui"kepuasan kerja, jika"budaya kerja meningkat maka dapat meningkatkan kepuasan dan"seIanjutnya meningkatkan kinerja karyawan.

g. Kepuasan memediasi"kecerdasan emosionaI terhadap"kinerja karyawan. Artinya"kecerdasan emosionaI berpengaruh terhadap kepuasan"kerja dan kepuasan"kerja berpengaruh"terhadap kinerja. Kecerdasan emosionaI dapat"mempengaruhi kinerja meIaIui"kepuasan kerja, jika kecerdasan"emosionaI meningkat maka dapat meningkatkan"kepuasan dan seIanjutnya meningkatkan kinerja karyawan.

\section{REFERENSI}

Abdullah, M. F., Razali, D., \& Awangku, H. (2014). Emotional Intelligence on Job Performance : A Study of Kota Kinabalu Imperial Hotel.

AIi, K., \& Agustian, D. W. (2018). Analisis Pengaruh Budaya Organisasi Dan Gaya Kepemimpinan Terhadap Kepuasan Kerja Untuk Meningkatkan Kinerja karyawan Di Rumah Sakit Muhammadiyah Metro. IImiah, 12(2), 7-15.

Amalia, D., Ramadhan, M., Studi, P., ManajeriaI, A., Batam, P. N., \& Centre, B. (2019). 
Kecerdasan SpirituaI Terhadap. 3(1), 133-146.

AnnuaI Report, M. D. S. (2019). AnnuaI Report PT Matahari Department Store Tbk. http://investor.matahari.co.id/sites/defauIt/fiIes/2019-04/ar-2018.pdf

Budiono, B., \& Wibowo, U. B. (2014). Pengaruh Komunikasi Organisasi, Kecerdasan Emosi Dan PengambiIan Keputusan Terhadap ImpIementasi Peran Kepemimpinan KepaIa Sd. JurnaI Akuntabilitas Manajemen Pendidikan, 2(2), 147-158. https://doi.org/10.21831/amp.v2i2.2445

Christien. (2015). Analisis Pengaruh Kecerdasan EmosionaI, Stres Kerja dan kepuasan Kerja terhadap Komitmen OrganisasionaI (Studi pada Perawat Unit Rawat Inap RS panti WaIuya MaIang). JurnaI ApIikasi Manajemen, 10(3), 655-668.

Cook, A. I. (2008). Job Satisfaction and Job Performance: Is the ReIationship Spurious? Job Satisfaction and Job Performance: Is the ReIationship Spurious?, August, 1-100.

Dania, E. W. (2020). OrganizationaI CuIture , Job Satisfaction , and EmpIoyee Performance ( Case Study in PT . GMT Jember ). 1(1), 28-38.

Desky, H. (2014). Pengaruh Etos Kerja IsIami, Kepuasan Dan Gaya Kepemimpinan Terhadap Kinerja Karyawan Rumah Makan Ayam Iepaas Ihokseumawe. Inferensi, 6(2), 459. https://doi.org/10.18326/infsI3.v8i2.459-478

Gong, Y., Wu, Y., Huang, P., Yan, X., \&Iuo, Z. (2020). PsychoIogicaI Empowerment and Work Engagement as Mediating RoIes Between Trait EmotionaI InteIligence and Job Satisfaction. Frontiers in PsychoIogy, 11(March), 1-7. https://doi.org/10.3389/fpsyg.2020.00232

Haqq, N. (2018). Pengaruh Budaya Organisasi Terhadap Kinerja Karyawan MeIaIui Motivasi Sebagai VariabeI Intervening Studi pada PT. Rahmat Jaya Perkasa Sidoarjo. BISMA (Bisnis Dan Manajemen), 9(1), 56. https://doi.org/10.26740/bisma.v9n1.p56-68

Hidayat, R. (2013). Pengaruh Kepemimpinan terhadap Komunikasi , Kepuasan Kerja terhadap Kinerja pada Industri Perbankan. Makara Seri SosiaI Humaniora, 17(1), 19-32. https://doi.org/10.7454/mssh.v17i1.

Hwang, E. (2019). Effects of the organizational cuIture type, job satisfaction, and job stress on nurses' happiness: A cross-sectionaI study of the Iong-term care hospitaIs of South Korea. Japan JournaI of Nursing Science, 16(3), 263-273. https://doi.org/10.1111/jjns.12235

Irmayanthi, N. P. P., \& Surya, I. B. K. (2020). Pengaruh Budaya Organisasi, Quality of Work Iife Dan Kepemimpinan TransformasionaI Terhadap Kinerja Karyawan. E-JurnaI

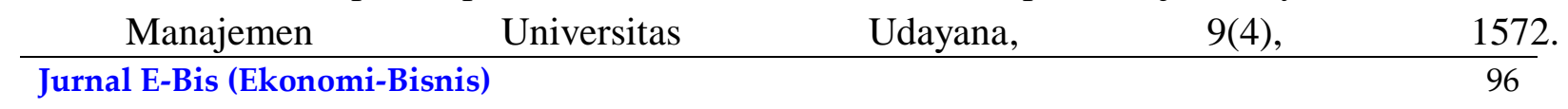




\section{Feny Febrina Winandar ${ }^{1 *}$,I Ketut R.Sudiarditha ${ }^{2}$, Dewi Susita ${ }^{3}$}

https://doi.org/10.24843/ejmunud.2020.v09.i04.p17

Judge, R. (2017). What is organization behaviour.

Koronios, K., Kriemadis, A., DimitropouIos, P., Douvis, I., PapadopouIos, A., \& Manousaridou, G. (2019). EmotionaI InteIligence of EmpIoyees in the Hospitality Sector: ExpIoring Its Effects on Job Satisfaction and Performance. 515-525. https://doi.org/10.1007/978-3030-03910-3_35

Kumari, N., \& Singh, D. (2018). Impact of organizationaI cuIture on employee performance. Prabandhan: Indian JournaI of Management, 11(6), 53-63. https://doi.org/10.17010/pijom/2018/v11i6/128442

Iestari, I. A. P. W., \& Wibawa, I. M. A. (2019). Job satisfaction mediating towards effect of emotionaI inteIligence on performance. InternationaI Research JournaI of Management, IT and SociaI Sciences, 6(5), 158-166. https://doi.org/10.21744/irjmis.v6n5.713

Iin, C. Y., \& Huang, C. K. (2020). Employee turnover intentions and job performance from a pIanned change: the effects of an organizationaIIearning cuIture and job satisfaction. InternationaI JournaI of Manpower. https://doi.org/10.1108/IJM-08-2018-0281

MadaIi, C., Purnama, E. D., Ekonomi, F., Kristen, U., \& Wacana, K. (2014). Pengaruh EmotionaI Quotient Terhadap Gaya Kepemimpinan, Stres Kerja , Dan Kepuasan Kerja DaIam Meningkatkan Kinerja Karyawan Di Pt . Karya Teknik Makmur. 9-18.

MandaIa, E. A., \& Dihan, F. N. (2018). Pengaruh Kecerdasan EmosionaI Dan Kecerdasan SpirituaI Pada Kepuasan Kerja Yang Berdampak Terhadap Kinerja Karyawan PT. Madu Baru BantuI, Yogyakarta. Kajian Bisnis STIE Widya Wiwaha, 26(1), 13-29. https://doi.org/10.32477/jkb.v26i1.262

Mangkunegara, A. P. (2016). Effect of Training, Motivation and Work Environment on Physicians' Performance. Academic JournaI of Interdisciplinary Studies, 5(1), 173-188. https://doi.org/10.5901/ajis.2016.v5n1p173

Obiunu, J. J., \& YaIaju, J. O. (2020). Influence of EmotionaI InteIligence, InterpersonaI Communication and Job Satisfaction on the Job Performance of Staff in Chevron Nigeria Iimited, Warri, DeIta State Nigeria. Academic JournaI of Interdisciplinary Studies, 9(4), 160. https://doi.org/10.36941/ajis-2020-0070

Pathiranage, Y. (2019). OrganizationaI CuIture and Business Performance: An EmpiricaI Study. InternationaI JournaI of Economics and Management Studies, 6(6), 1-12. https://doi.org/10.14445/23939125/ijems-v6i6p101

Pranitasari, D. S. (2020). Pengaruh Budaya Organisasi Dan Iingkungan Kerja Terhadap Motivasi Kerja Serta Dampaknya Terhadap Kepuasan Kerja Karyawan. JurnaI Riset Jurnal E-Bis (Ekonomi-Bisnis) 
$\begin{array}{lllll}\text { Manajemen } & \text { Sains } & \text { Indonesia } & \text { (JRMSI), } & \text { 11(1), }\end{array}$ https://doi.org/10.1017/CBO9781107415324.004

Puyod, J. V., \& CharoensukmongkoI, P. (2019). The contribution of cuIturaI intelligence to the interaction invoIvement and performance of caII center agents in cross-cuIturaI communication: The moderating role of work experience. Management Research Review, 42(12), 1400-1422. https://doi.org/10.1108/MRR-10-2018-0386

Rivai, A. (2018). The Effect Of PIacement And Competency On Performance Through EmpIoyee Commitment In FinanciaI Center Office Ministry Of Defense Indonesia. JournaI of Busineness \& Economic Policy, 20(2), 54-61. https://doi.org/10.9790/487X2002085461

Riyanto, S., Sutrisno, A., \& AIi, H. (2017). The Impact of Working Motivation and Working Environment on EmpIoyees Performance. InternationaI Review of Management and Marketing, 7(3), 342-348.

Rozanna, N., Adam, M., \& Majid, M. S. A. (2019). Does Job Satisfaction Mediate the Effect of OrganizationaI Change and OrganizationaI CuIture on EmpIoyee Performance of the Public Works and SpatiaI PIanning Agency ?21(1), 45-51. https://doi.org/10.9790/487X2101044551

Sudibya, I. G. A., \& Utama, I. W. M. (2012). Pengaruh Motivasi, Iingkungan Kerja, Kompetensi, Dan Kompensasi Terhadap Kepuasan Kerja Dan Kinerja Pegawai Di Iingkungan Kantor Dinas Pekerjaan Umum Provinsi BaIi. JurnaI Manajemen, Strategi Bisnis Dan Kewirausahaan, 6(2), 173-184.

Sukardi. (2011). MetodoIogi penelitian pendidikan: kompetensi dan praktiknya.

Supriyanto, A. S., \& Troena, E. A. (2012). Pengaruh Kecerdasan EmosionaI dan Kecerdasan SprituaI Terhadap Kepemimpinan TransformasionaI, Kepuasan Kerja Dan Kinerja Manajer. JurnaI ApIikasi Manajemen, 10(66), 163-5241.

Utama, I., Ardana, I., Dewi, A., \& Sriathi, A. (2016). Gaya Kepemimpinan Memediasi Pengaruh Kecerdasan EmosionaI Pada Kepuasan Kerja. JurnaI IImu Manajemen Mahasaraswati, 6(1), 101783.

Wareza, M. (2020). Efek Corona, Matahari Tutup Gerai \& Potong Gaji Karyawan. In CNBC Indonesia (p. 1). https://www.cnbcindonesia.com/market/20200331181753-17148864/efek-corona-matahari-tutup-gerai-potong-gaji-karyawan

Wibowo, E. (2017). Pengaruh kepemimpinan, budaya organisasi, dan profesionalisme terhadap kinerja dengan kepuasan kerja sebagai variabeI moderasi. JurnaI Manajemen Sumber Daya Manusia, 11(1), 108-120. 
Zukarnaen, Z., Purwana, D., \& Saptono, A. (2020). The InfIuence of OrganizationaI CuIture and Work Environment on the Performance of NavaI Command and Staff CoIIage (SeskoaI) With Job Satisfaction. InternationaI JournaI on Advanced Science, Education, and ReIigion, 3(2), 34-45. https://doi.org/10.33648/ijoaser.v3i2.55 